\title{
TO STUDY THE THERAPEUTIC RESPONSE FOLLOWING HIGHLY ACTIVE ANTIRETROVIRAL THERAPY
}

\author{
Alagamuthu Veni' ${ }^{1}$ Sappani Kasipandian², Natesan Kathirvel Senthilnathan ${ }^{3}$
}

${ }^{1}$ Assistant Professor, Department of Medicine, K. A. P. Viswanatham Government Medical College, Tiruchirapalli, Tamilnadu. ${ }^{2}$ Associate Professor, Department of Medicine, K. A. P. Viswanatham Government Medical College, Tiruchirapalli, Tamilnadu. ${ }^{3}$ Associate Professor \& HOD, Department of Medicine, K. A. P. Viswanatham Government Medical College, Tiruchirapalli, Tamilnadu.

\section{ABSTRACT}

\section{BACKGROUND}

Acquired Immunodeficiency Syndrome (AIDS) is an infectious disease caused by Human Immune Deficiency Virus (HIV). It affects all the organ systems in the human body and has been studied so extensively in a short period worldwide. Highly Active Antiretroviral Therapy (HAART) for treatment of HIV infection has improved steadily, and more recently new drugs have been approved, offering dosing convenience and improved safety profiles. HIV infection is more prevalent in the active reproductive age group of 20-50 years especially in employed migrant youths, drivers, constructional workers and married couples with male predominance.

Aim- To study the Clinical stage response, Immunological response and Functional status improvement to Highly Active Antiretroviral Therapy.

\section{MATERIALS AND METHODS}

This study was conducted in 100 People Living With HIV \& AIDS (PLWHA) more than 20 years of age only after thorough history, clinical and systemic examination who have attended the General Medicine OPs, Wards and ART centre, Mahatma Gandhi Memorial Government (Tertiary Care) Hospital, Tiruchirapalli, Tamilnadu, India.

\section{RESULTS}

Our study showed high prevalence of HIV among 20-50 years of active reproductive age group especially in employed migrant youths, drivers, constructional workers, married couples with male predominance. The incidence of TB was more common in PLWHA with CD4 count less than 200/ $\mu$ L. After appropriate Antituberculosis Treatment (ATT) and HAART, there was significant improvement in clinical stages, functional, mean CD4 counts, and immunological success around $97 \%$ in this study.

\section{CONCLUSION}

Initiation of HAART was associated with increase in body weight, immunological response, functional status, mental wellbeing and decrease in occurrence of opportunistic infections (OI). PLWHA without OI have good clinical stage improvement than with OI. Opportunistic infections are more common in bedridden category (88\%) than working category (66.7\%). CD4 count response following HAART was more in working category than the bedridden category.

\section{KEYWORDS}

PLWHA, HAART, Opportunistic Infections.

HOW TO CITE THIS ARTICLE: Veni A, Kasipandian S, Senthilnathan NK. To study the therapeutic response following highly active antiretroviral therapy. J. Evolution Med. Dent. Sci. 2017;6(62):4552-4557, DOI: 10.14260/Jemds/2017/985

\section{BACKGROUND}

AIDS also called slim disease and strictly speaking is the last stage of HIV infection. It spreads worldwide with various adverse health and economic implications, particularly in the developing world. As on 2007 total number of PLWHA in the world was 33.2 million, of these 15.4 million were women and 2.5 million were children. Total deaths were 2.1 million and in adults 1.7 million. The total number of TB cases and deaths in PLWHA was estimated to be 1.39 million cases (15\% of all incident cases) and 0.48 million deaths, which was $24 \%$ of the estimated 2 million HIV deaths in 2007.1

Financial or Other, Competing Interest: None.

Submission 24-06-2017, Peer Review 21-07-2017,

Acceptance 27-07-2017, Published 03-08-2017.

Corresponding Author:

Dr. Sappani Kasipandian,

"Devi Illam", No.:3/423/5,

Meenakshi Amman Street,

Opp. to Pandi Kovil,

Pandian Nagar,

Madurai - 625020.

E-mail: sankarkasipandian@yahoo.com

DOI: $10.14260 /$ jemds $/ 2017 / 985$
As on 2007, in India, total number of PLWHA was 2.4 million and HIV prevalence in adults was $0.34 \%(0.25 \%$ 0.43\%). Among PLWHA, 39\% were females, 3.5\% were children. Considering the fact that the lifetime risk of developing TB disease is between 50-60\%, In India, free AntiRetroviral Therapy (ART) was introduced in April 2004, as a component of care, support and treatment, in National AIDS Control Programme (NACP). Initiation of HAART reduces risk of further HIV-related morbidity and mortality, and also the incidence of TB even in high TB prevalence countries. ${ }^{1}$ Among the PLWHA who are without HAART 30\% will develop AIDS in 3 years and 90\% will develop AIDS within 10 years. HIV infection in India declined drastically from 5.5 million in 2005 to below 2.5 million in 2007.

\section{Medical Eligibility to Start HAART ${ }^{2}$}

If CD4 count testing is available- a) start HAART if CD4 count is less than 200 cells/ $\mu \mathrm{L}$ at any clinical stage, b) in WHO clinical stage IV, start HAART irrespective of CD4 count levels, c) WHO clinical stage III, consider HAART if CD4 count is less than 350 cells $/ \mu \mathrm{L}$ and initiate HAART if CD4 count less than 
200 cells $/ \mu \mathrm{L}$. If CD4 count testing is not available initiate HAART for patient with WHO clinical stage III \& IV.

\section{Selecting the HAART Regimen}

In general, HAART should not be initiated during severe acute opportunistic infection or other severe illnesses. Efavirenz based regimen for HIV patient on ATT, Stavudine based regimen if $\mathrm{Hb}$ less than $8 \mathrm{~g} \%$, and Non-Nevirapine based regimen for known liver diseases.

Adherence to HAART depends upon the number of missing doses per month, if the missing doses were increased then the adherence rate will be decreased.

Treatment failures of HAART ${ }^{3,4}$ are: virological failure due to increased viral load, immunological failure due to decreased CD4 count and Clinical failure due to increased opportunistic infection.

Laboratory Monitoring during HAART are: CD4+ cell count, HIV RNA determinations, HIV resistance testing and TB/HIV co-infection assessment.

\section{Precautions}

When Rifampicin combined with Protease Inhibitors and Nevirapine it may decrease the levels of all other drugs and decreasing the effectiveness of HAART, increasing Rifampicin level leading to hepatotoxicity. Efavirenz based HAART regimen should be given when combined to ATT. Fluconazole should be given along with ATT, and HAART in case of oral candidiasis which also results in hepatic toxicity.

\section{Aim of the Study}

To study the Clinical stage response, Immunological response and Functional status improvement to Highly Active Antiretroviral Therapy.

\section{MATERIALS AND METHODS Study Population}

This study was conducted on 100 PLWHA adult patients only after thorough clinical and systemic examinations who attended General Medicine OPs, Wards and the ART centre, Mahatma Gandhi Memorial Govt. (Tertiary Care) Hospital attached to K.A.P.V. Govt. Medical College, Tiruchirapalli, Tamil Nadu, India.

\section{Consent}

Prior written consent was obtained from all the patients included in this study in their own mother tongue.

\section{Study Period and Duration}

December 2015 to January 2017 Thirteen months.

\section{Study Design}

Descriptive study.

\section{Ethical Committee Approval}

Obtained from the Institutional Ethical Committee.

\section{Inclusion Criteria}

1. Patient's age should be more than 20 years.

2. The diagnosis of HIV confirmed as per WHO criteria.

3. Initiation of HAART according to WHO criteria.

\section{Exclusion Criteria}

1. The patients who have already received treatment with HAART outside.

2. The patients who were already diagnosed with diabetes and tuberculosis and on treatment.

\section{Data Collection}

All 100 PLWHA were thoroughly evaluated by taking detailed history regarding occupation, educational status, personal history, family history, marital, couples and couples' reactivity status, children status, general examinations, systemic examination, including OI, functional status and appropriate investigations as per proforma. Patient's weight was recorded during each visit. Clinical staging was determined by clinical examinations and functional status as per WHO clinical staging.

\section{Pre and Post-HAART Investigations \& followup-}

TC, DC, HB, ESR, Platelet count, Liver function test, Blood Sugar, Urea, Serum Creatinine, Urine routine examination, $\mathrm{X}$ ray chest $\mathrm{PA}$ view, sputum for $\mathrm{AFB}, \mathrm{CD} 4$ count, OI, clinical staging analysis I to IV as per WHO references, Functional status assessment before, after and 12 months of HAART and other specific tests.

\section{HIV Diagnostic Criteria}

Three rapid HIV test kits based on different antigens/principle were used and the blood samples were processed for HIV screening. The test results may be positive, negative or indeterminate.

Positive Negative Indeterminate

Test kit 1 (Microlisa) Positive

Test kit 2 (PAREEKSHAK) Positive

Case reported as positive

\section{Immunological Assessment}

CD4 Count Analysis: The specimens were collected and analysed by the BD FACScalibur flow cytometer (Becton Dickinson \& Company, San Jose, USA) from May 2018 and PARTEC cyflow counter.

\section{Functional Status Assessment}

As per NACO guidelines, functional status of the patients was assessed before, and after starting 6 months, 12 months of HARRT and graded as WAB.

\section{W - Working}

Able to perform usual work in or out of the house, harvest, normal activities of playing,

A - Ambulatory

Able to perform activities of daily living but not able to work.

\section{B - Bedridden}

Not able to perform activities of daily living.

Pulmonary TB was diagnosed by $\mathrm{CBC}$, radiological examination, chest X-ray, microscopic examination of sputum stained by Ziehl-Neelsen technique as sputum positive and sputum negative. 
Extrapulmonary TB like TB lymphadenitis diagnosed by fine needle aspiration cytology (FNAC), TB meningitis/meningoencephalitis diagnosed by CSF analysis, culture for AFB, Brain TB diagnosed by CT Brain and abdominal TB Lymphadenitis diagnosed by USG abdomen.

HAART was initiated if the patient meets the WHO criteria for starting treatment. Initiation of HAART is based on CD4 count and WHO clinical stage. Before starting HAART, TB infection was specifically investigated and treated with ATT as per RNTCP guidelines.

\section{HAART Regimens Commonly used are,}

Regimen I = Stavudine + Lamivudine + Nevirapine $-(\mathrm{S}+\mathrm{L}+\mathrm{N})$, Regimen II = Stavudine + Lamivudine + Efavirenz $-(\mathrm{S}+\mathrm{L}+\mathrm{E})$ Regimen III $=$ Zidovudine + Lamivudine + Nevirapine $(\mathrm{Z}+\mathrm{L}+\mathrm{N})$,

Regimen IV $=$ Zidovudine + Lamivudine + Efavirenz $(\mathrm{Z}+\mathrm{L}+\mathrm{E})$,

Regimen $\mathrm{V}=$ Change over from one to other regimen.

\section{Statistical Analysis}

The information collected regarding all the selected cases were recorded in a master chart. Data analysis was done with the help of computer by using SPSS 16 software and Sigma stat 3.5 version. Using this software, mean, standard deviation, ' $p$ ' value were calculated through Student ' $t$ ' test, Paired ' $\mathrm{t}$ ' test and $\mathrm{P}$ value of $<0.05$ was taken as significant.

\section{RESULTS}

In this study, 100 PLWHA were selected as per selection criteria and analysed. It revealed the following results.

\section{Age Distribution}

In this study, most of the patients (92\%) were in the active reproductive age group of 20 - 50 years, which shows the prevalence of HIV is high among this group.

\begin{tabular}{|c|c|c|c|}
\hline Age in Years & Male & Female & Total \\
\hline $20-30$ & 2 & 18 & 20 \\
\hline $31-40$ & 28 & 17 & 45 \\
\hline $41-50$ & 15 & 12 & 27 \\
\hline$>50$ & 7 & 1 & 8 \\
\hline Total & $\mathbf{5 2}$ & $\mathbf{4 8}$ & $\mathbf{1 0 0}$ \\
\hline Table 1. Age and Sex Distribution (n=100) \\
\hline
\end{tabular}

\section{Sex Distribution}

This study showed increased HIV prevalence in males compared to females, $52 \%$ vs. $48 \%$.

\section{Employment Status and Risk of HIV}

In this study, total employed patients were $80(80 \%)$. All the $52(100 \%)$ male patients were employed, 28 (58\%) females were employed and 20 (42\%) females were unemployed. Most of them were migrant employed youths particularly drivers and constructional workers.

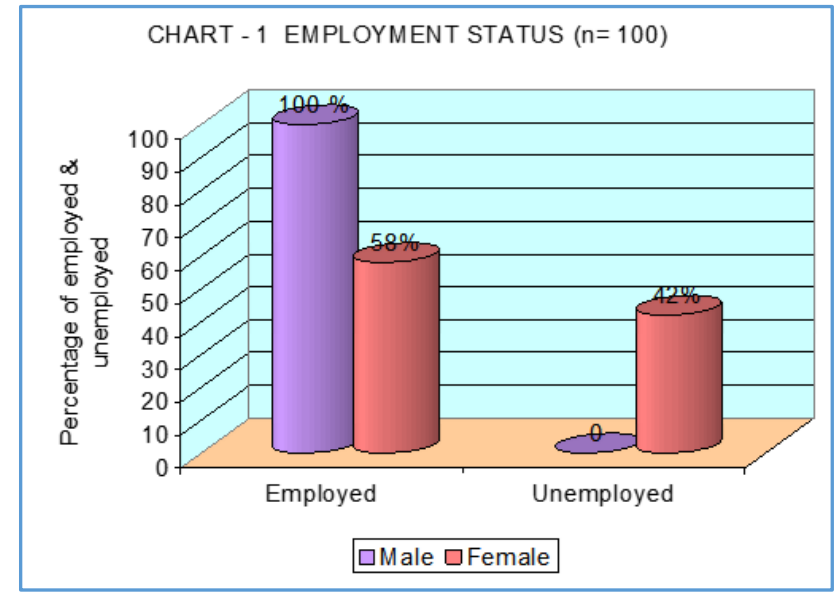

\section{Marital Status \& Family Wise Distribution}

In this study, $80 \%$ of PLWHA were married couples, $9 \%$ were female widowers and 11\% were unmarried. 54\% showed both couples were HIV positive which stressed the importance of preventive measures aimed at preventing the transmission between couples through education and adaptation of safe sexual practices. $32 \%$ patients were discordant couples and remained as discordant throughout the study.

\section{Distribution of Opportunistic Infections in PLWHA}

In this study, $37 \%$ of patients had oral candidiasis, $32 \%$ of patients had both pulmonary and extrapulmonary TB, 10\% had recurrent bacterial infections, whereas $40 \%$ were free from any OI. They were significantly reduced after HAART with significant $P$ value $<0.001$.

OIs are more common in bedridden groups (88\%) than the working groups (66.66\%).

CHART - 2 OPPOURTUNISITIC INFECTIONS $(n=100)$

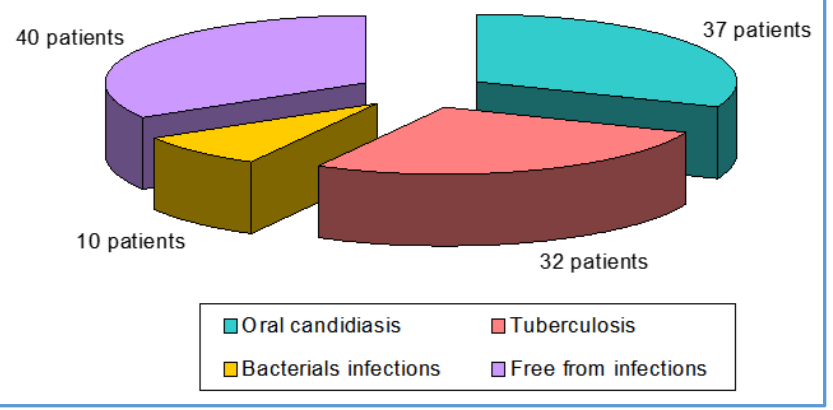

TB in PLWHA in relation to CD4 Count

In this study, $21 \%$ of pulmonary $\mathrm{TB}$ and $11 \%$ of extrapulmonary TB cases were diagnosed in PLWHA with CD4 count less than 200 cells/ $\mu \mathrm{L}$. Of these $21 \%$ of pulmonary TB patients, sputum was positive in $14 \%$ and negative in $7 \%$ of the patients. They were initially started on ATT and HAART started subsequently after 2 weeks to 2 months as soon as TB treatment is tolerated. 


\begin{tabular}{|c|c|c|c|}
\hline HIV \& TB Co-infection & Male & Female & Total \\
\hline $\begin{array}{c}\text { Pulmonary TB smear } \\
\text { positive }\end{array}$ & 10 & 4 & 14 \\
\hline $\begin{array}{c}\text { Pulmonary TB smear } \\
\text { Negative }\end{array}$ & 5 & 2 & 7 \\
\hline Extrapulmonary TB & 7 & 4 & 11 \\
\hline Total & $\mathbf{2 2}$ & $\mathbf{1 0}$ & $\mathbf{3 2}$ \\
\hline \multicolumn{2}{|c|}{ Table 2. HIV and TB Co-infection (n=100) } \\
\hline
\end{tabular}

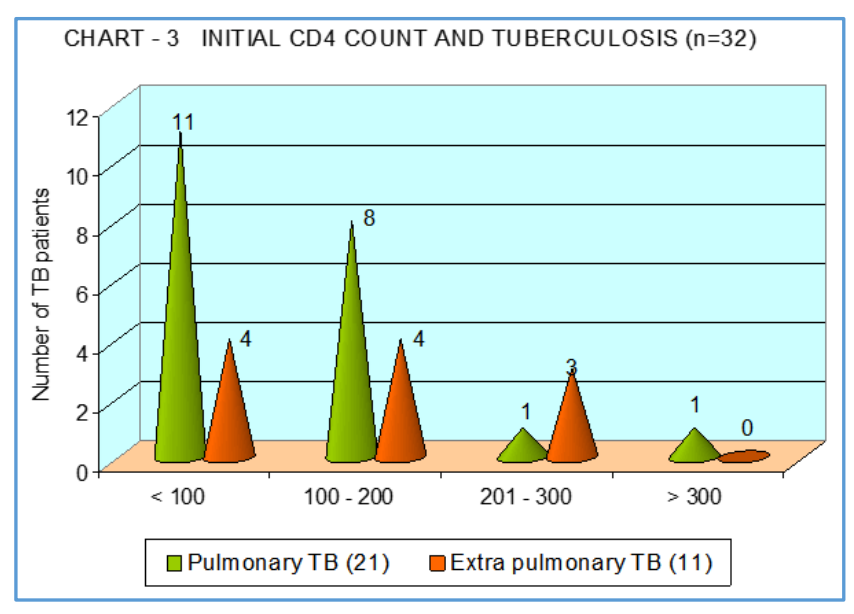

\section{HAART Regimen}

In this study, $34 \%$ patients received HAART regimen I, and $21 \%$ patients received HAART regimen III. Change over from one regimen to another regimen was $43 \%$ which was mainly due to rashes induced by Nevirapine and hepatotoxicity by Rifampicin containing ATT, for that Efavirenz substituted for Nevirapine. Stavudine was preferred to Zidovudine for severe anaemic patients. Success rate was high with regimen I $(34 \%)$ than with regimen III $(21 \%)$ and change over HAART regimen was 43\%. After 12 months of HAART the immunological success rate was $93 \%$ and immunological failure rate was $7 \%$.

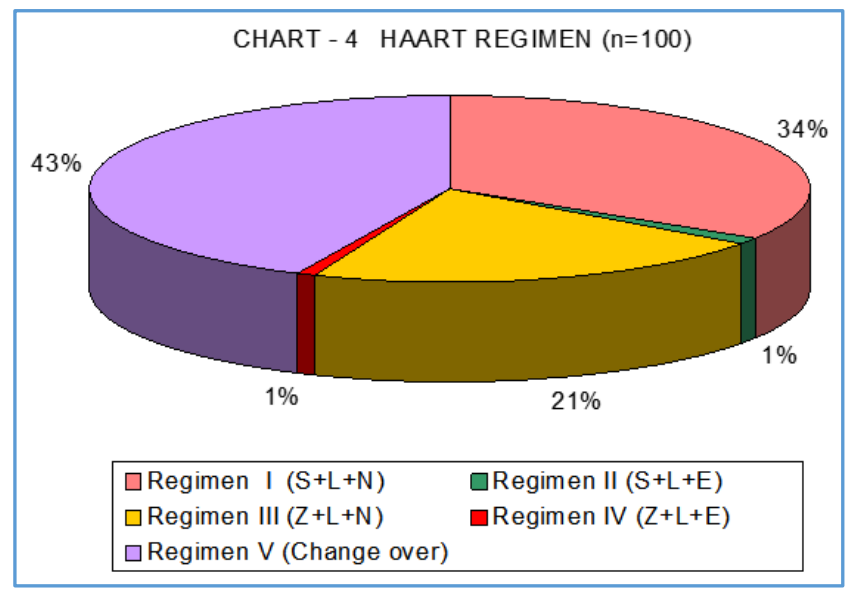

\section{WHO HIV Clinical Stage Improvement following HAART}

In this study of the 100 PLWHA, $10(3 \mathrm{M}+7 \mathrm{~F})$ patients were in clinical stage I at pre-HAART and after 6, 12 months of HAART also they were in the clinical stage I without any deterioration. Finally, after 6 and 12 months of HAART, the total number of clinical stage I patients were markedly increased to $87(42 \mathrm{M}+45 \mathrm{~F})$ and $94(47 \mathrm{M}+47 \mathrm{~F})$ from other clinical stages. PLWHA without OI have more clinical stage improvement to HAART than with OI.

In this study, of the 100 PLWHA, $3(2 \mathrm{M}+1 \mathrm{~F})$ patients were in clinical stage II at pre-HAART and after 6 months of HAART they markedly improved to clinical stage I and continued to be in clinical stage I after 12 months of HAART also.

In this study of the 100 PLWHA, $69(38 \mathrm{M}+31 \mathrm{~F})$ patients were in clinical stage III at pre-HAART. Of these, $60(30 \mathrm{M}+$ $30 \mathrm{~F}$ ) patients markedly improved to clinical stage I after 6 months of HAART and persistently continued in clinical stage I after 12 months of HAART also. Of the remaining $9(8 \mathrm{M}+$ $1 \mathrm{~F})$ patients of clinical stage III after 6 months of HAART, there was no improvement in $5(5 \mathrm{M})$ patients and $4(4 \mathrm{M})$ patients improved to stage II. Subsequently after 12 months of HAART, of the $5(5 \mathrm{M})$ stage III patients, $4(4 \mathrm{M})$ patients improved to clinical stage I, $1(1 \mathrm{M})$ patient deteriorated to clinical stage IV. Of the $4(3 \mathrm{M}+1 \mathrm{~F})$ stage II patients, $3(2 \mathrm{M}+$ $1 \mathrm{~F})$ patients improved to clinical stage I and $1(1 \mathrm{M})$ patient remained in the stage II. Finally, after 12 months of HAART, of these 69 stage III patients, 66 patients markedly improved to stage I and 2 patients improved to clinical stage II and 1 patient deteriorated to clinical stage IV.

In this study of the 100 PLWHA, 18 patients were in stage IV at pre-HAART. Of these, $15(7 \mathrm{M}+8 \mathrm{~F})$ patients improved to stage I after 6 months of HAART and 14 patients continued to be in stage I and 1 patient deteriorated to stage IV after 12 months of HAART. Of the remaining 4 stage IV patients after 6 months of HAART, 3 patients improved to stage III, 1 patient improved to stage II and another 1 patient deteriorated to stage IV. After 12 months of HAART of these 5 stage IV patients, 3 patients were in stage IV without any clinical stage improvement and 2 patients improved to stage I. Finally, after 12 months of HAART, of these 18 stage IV patients, 15 $(83.3 \%)$ patients markedly improved to stage I and only 3 (16.63\%) patients did not improve.

In this study after 6 months of HAART, an increase in clinical stage I from $10 \%(3 \mathrm{M}+7 \mathrm{~F})$ to $87 \%(42 \mathrm{M}+45 \mathrm{~F})$ is mainly due to the patients who had improved in the clinical status from stage III to stage I i.e. marked change in stage III from $69 \%(38 \mathrm{M}+31 \mathrm{~F})$ to stage $\mathrm{I}, 7 \%(6 \mathrm{M}+1 \mathrm{~F})$ and in stage IV from $18 \%$ to $1 \%$. At the end of 12 months of HAART, $94 \%$ $(47 \mathrm{M}+47 \mathrm{~F})$ of patients were in stage I, $2 \%(2 \mathrm{M})$ in stage II, $0 \%$ in stage III and $4 \%(3 \mathrm{M}+1 \mathrm{~F})$ in stage IV. These are statistically significant with $P$ value $<0.01$.

\begin{tabular}{|c|c|c|c|c|c|c|c|c|c|}
\hline WHO Stage Improvement & \multicolumn{3}{|c|}{ Pre-HAART } & \multicolumn{3}{c|}{$6^{\text {th }}$ Month of HAART } & \multicolumn{3}{c|}{ 12th Month of HAART } \\
\hline Stage & Male & Female & Total & Male & Female & Total & Male & Female & Total \\
\hline I & 3 & 7 & 10 & 42 & 45 & 87 & 47 & 47 & 94 \\
\hline II & 2 & 1 & 3 & 3 & 2 & 5 & 2 & 0 & 2 \\
\hline III & 38 & 31 & 69 & 6 & 1 & 7 & 0 & 0 & 0 \\
\hline IV & 9 & 9 & 18 & 1 & 0 & 1 & 3 & 1 & 4 \\
\hline Total & $\mathbf{5 2}$ & $\mathbf{4 8}$ & $\mathbf{1 0 0}$ & $\mathbf{5 2}$ & $\mathbf{4 8}$ & $\mathbf{1 0 0}$ & $\mathbf{5 2}$ & $\mathbf{4 8}$ & $\mathbf{1 0 0}$ \\
\hline \multicolumn{8}{|c}{} \\
\hline
\end{tabular}




\section{Weight Increment}

The change in weight after HAART as calculated by Paired " $t$ " test is statistically significant with P value $<0.001$ (99\% confidence interval). Average increment of weight in this study was $5 \mathrm{~kg}$.

\begin{tabular}{|c|c|c|c|c|c|c|}
\hline Pair & Mean & SD & SE of Mean & Lower & Upper & Significance p Value \\
\hline Pre-HAART weight & & & & & & \\
\hline Post-HAART weight & 4.59 & 4.675 & 0.467 & 3.39 & 5.79 & $<0.001$ Sig \\
\hline Pre-HAART CD4 count & & & & & & $<0.001$ Sig \\
\hline Post-HAART CD4 count & 220.7 & 158.45 & 15.85 & 199.9 & 261.5 & \\
\hline \multicolumn{7}{|l}{ Table 4. Weight Increment Following HAART (n=100) } \\
\hline
\end{tabular}

\section{Immunological Response}

In this study, of the 30 Working category cases of PLWHA, CD4 count $>400$ cells $/ \mu \mathrm{L}$ in the pre-HAART was $1(3.3 \%)$ and it increased to $8(26.66 \%)$ and $15(50 \%)$ number of patients after 6 and 12 months of HAART. In this study, of the 53 ambulatory category cases of PLWHA, CD4 count $>400$ cells/ $\mu \mathrm{L}$ in the pre-HAART was in $1(1.89 \%)$ patient only and increased to $15(28.30 \%)$ and $21(39.62 \%)$ number of patients after 6 and 12 months of HAART. In this study, of the 17 Bedridden category of PLWHA, CD4 count $>400$ cells $/ \mu \mathrm{L}$ in the pre-HAART was only $1(5.88 \%)$ patient only and increased to $3(17.65 \%)$ and $6(35.29 \%)$ in number after 6 and 12 months of HAART. In this study, CD4 count response following HAART was more in Working category than the Bedridden. In this study after 6 months of HAART, the mean CD4 count had increased from 81 cells/ $\mu \mathrm{L}$ to 189 cells $/ \mu \mathrm{L}$ and the average increase in CD4 count was 108 cells/ $\mu \mathrm{L}$. Statistical analysis using paired " $\mathrm{T}$ " test showed significant $\mathrm{P}$ value $<0.001$. $93 \%$ showed immunological success and $7 \%$ showed a decline in CD4 count, immunological failure after HAART.

\section{Functional Status Improvement following HAART}

In this study, of the 100 PLWHA, $30(13 \mathrm{M}+17 \mathrm{~F})$ patients were in the Working category at pre-HAART and continued to be in the Working category after 6 and 12 months of HAART.

In this study of the 100 PLWHA, $53(27 \mathrm{M}+26 \mathrm{~F})$ patients were in the Ambulatory category at pre-HAART and after 6 months of HAART, $8(5 \mathrm{M}+3 \mathrm{~F})$ patients continued to be in the Ambulatory category and $45(22 \mathrm{M}+23 \mathrm{~F})$ patients improved to Working category and continued as Working category after 12 months of HAART also. After 12 months of HAART of the remaining $8(5 \mathrm{M}+3 \mathrm{~F})$ Ambulatory category patients, $5(5 \mathrm{M})$ patients improved to working category, $1(1 \mathrm{~F})$ patient continued as Ambulatory category and $2(1 \mathrm{M}+1 \mathrm{~F})$ patients worsened to Bedridden category.

In this study of the 100 PLWHA, $17(12 \mathrm{M}+5 \mathrm{~F})$ were in the Bedridden category at pre-HAART and after 6 months of HAART, $11(8 \mathrm{M}+3 \mathrm{~F})$ patients improved to Ambulatory category and $6(5 \mathrm{M}+1 \mathrm{~F})$ patients improved to working category. After 12 months of HAART, the $11(8 \mathrm{M}+3 \mathrm{~F})$ Ambulatory category patients also improved to Working category and finally all the $17(12 \mathrm{M}+5 \mathrm{~F})(100 \%)$ Bedridden patients markedly improved to working category.

It was evidenced by an increase in patients belonging to "W" class from $30 \%(13 \mathrm{M}+17 \mathrm{~F})$ to $79 \%(38 \mathrm{M}+41 \mathrm{~F})$ after 6 months of HAART and $97 \%(51 \mathrm{M}+46 \mathrm{~F})$ came under Working category after 12 months of HAART. It is statistically significant with "P" value $<0.01$. At the end of 12 months of HAART $97 \%(51 \mathrm{M}+46 \mathrm{~F})$ in Working category $1 \%(1 \mathrm{~F})$ Ambulatory and $2 \%(1 \mathrm{M}+1 \mathrm{~F})$ Bedridden.

In this study after 6 months of HAART $80(39 \mathrm{M}+41 \mathrm{~F})$ patients were in the Working category, $20(13 \mathrm{M}+7 \mathrm{~F})$ patients were in the Ambulatory category and after 12 months of HAART $97(51 \mathrm{M}+47 \mathrm{~F})$ patients were in the working category. $1(\mathrm{~F})$ patient was in the Ambulatory category and $2(1 \mathrm{M}+1 \mathrm{~F})$ patients were in the Bedridden category. This study showed that the functional status of PLWHA markedly improved after 12 months of HAART.

\begin{tabular}{|c|c|c|c|c|c|c|c|c|c|}
\hline $\begin{array}{c}\text { Functional Status } \\
\text { Improvement }\end{array}$ & \multicolumn{3}{|c|}{ Pre-HAART } & \multicolumn{3}{c|}{$6^{\text {th }}$ Month of HAART } & \multicolumn{3}{c|}{$1^{\text {th }}$ Month of HAART } \\
\hline Class & Male & Female & Total & Male & Female & Total & Male & Female & Total \\
\hline Bedridden & 12 & 5 & 17 & 0 & 0 & 0 & 1 & 1 & 2 \\
\hline Ambulatory & 27 & 26 & 53 & 14 & 7 & 21 & 0 & 1 & 1 \\
\hline $\begin{array}{c}\text { Working (Including house } \\
\text { work) }\end{array}$ & 13 & 17 & 30 & 38 & 41 & 79 & 51 & 46 & 97 \\
\hline Total & $\mathbf{5 2}$ & $\mathbf{4 8}$ & $\mathbf{1 0 0}$ & $\mathbf{5 2}$ & $\mathbf{4 8}$ & $\mathbf{1 0 0}$ & $\mathbf{5 2}$ & $\mathbf{4 8}$ & $\mathbf{1 0 0}$ \\
\hline \multicolumn{6}{c}{ Table 5. Functional Status Improvement Following HAART (n=100) } \\
\hline
\end{tabular}

\section{DISCUSSION}

In this study, the age of patients ranges from 20-75 years. Majority of patients belonged to the active reproductive age group of 20-50 years (92\%), mainly due to migration of young workers from other parts of the country, but in A.A. Takalkar et al study $2012^{5}$ only $77 \%$ of patients were in the sexually active age group of 26-45 years. As per the census India 2007, regarding age distribution of AIDS cases, majority of HIV cases (92\%) are in the age group of 20-50 years. The predominance of the males over the females $52 \%$ vs. $48 \%$ is closer to the census statistics of AIDS cases in India 2007 and $61 \%$ vs. $39 \%$ A.A. Takalkar et al study 2012.5

In this study, immunological success and failure rate was $93 \%$ and $7 \%$ compared to $80 \%$ and $20 \%$ of Kilaru KR el al study 2006. Smith CJ et al $2004^{7}$ study demonstrated immunological success in $84 \%$ patients with a median increase of CD4 cell count of 114 cells/ $\mu \mathrm{L}$. Vajpayee et al study 2007 showed an increase of CD4 cell count from a median 179 cells $/ \mu \mathrm{L}$ to 256 cells/ $\mu \mathrm{L}$ after HAART for a period of 6 months. 


\section{Marital Status}

In this study, $80 \%$ were married category and $9 \%$ widow category whereas $56 \%$ were in married category and $15.6 \%$ in widow category in a study by R Kamath et al $2013 .{ }^{7}$

\section{Opportunistic Infection}

In this study, $37 \%$ of PLWHA had oral candidiasis which is similar to $36 \%$ of oral candidiasis in Shobhana et al study 2004. In this study, $32 \%$ of PLWHA had both pulmonary and extrapulmonary TB whereas $36 \%$ of patients had TB in Ayyagiri et al study 1999.8

In this study, $21 \%$ of pulmonary TB cases were diagnosed in PLWHA with CD4 count less than 200 cells/ $\mu \mathrm{L}$ which is closer to Sudha Mishra et al study $2015^{9}$ who reported 23.5\% and Dhungana et al study 2008 who reported 23\% TB cases.

In this study, of the $21 \%$ of pulmonary TB patients, sputum was positive in $14 \%$ and sputum was negative in $7 \%$ of patients, whereas study conducted by R. Kamath et al $2013^{8}$ showed sputum positive in $43.7 \%$ and sputum negative in $18 \%$, and in Kavya et al study 2014 sputum was positive in $25 \%$ and sputum was negative in $10 \%$ of $\mathrm{TB}$ patients.

In this study, immune reconstitution after 6 months of HAART, median CD4 cell count rise was 108 cells/ $\mu \mathrm{L}$ with $\mathrm{p}$ value $<0.001$ and 118 cells $/ \mu \mathrm{L}$ with significant $\mathrm{p}$ value $<0.05$ in R. Kamath et al study $2013^{7}$ and 114 cells/ $\mu \mathrm{L}$ in another study by Smith. C.J. et al $2004 .^{6}$

\section{CONCLUSION}

Initiation of HAART was associated with marked increase in body weight, clinical stage improvement, functional status, immunological response, mental wellbeing and decrease in occurrence of OI. CD4 count response following HAART was more in working category than the bedridden category.

\section{REFERENCES}

[1] Cheien-Ching H, Mao-Yuan C, Chin-Fu H, et al. Improved outcomes of HIV-1 infected adults with tuberculosis in the era of HAART. AIDS 2003;17(18):2615-22.

[2] Volberding PA, Deeks SD. Antiretroviral therapy for HIV infection: promises and problems. JAMA 1998;279(17):1343-4.

[3] Monforte AA, Testa L, Adorni F, et al. Clinical outcome and predicative factors of failure of HAART in ART experienced patients in advanced stages of HIV-1 infection. AIDS 1998;12:1631-7.

[4] Haynes BF, Hale LP, Weinhold KJ, et al. Analysis of the adult thymus in reconstitution of $\mathrm{T}$ Iymphocytes in HIV-1 infection. J Clin Invest 1999;103(4):453-60.

[5] Takalkar AA, Saiprasad GS, Prasad VG, et al. Study of opportunistic infections in HIV seropositive patients admitted to community care centre, Andhra Pradesh, India. Biomedical Research 2012;23(1):139-42.

[6] Smith CJ, Sabin CA, Youle MS, et al. Factors influencing increases in CD4 cell counts of HIV positive persons receiving long term HAART. J Infect Dis 2004;190(10):1860-8.

[7] Kamath R, Sharma V, Pattanshetty S, et al. HIV-TB coinfection: clinic epidemiological determinants at an antiretroviral therapy center in Southern India. Lung India 2013;30(4):302-6.

[8] Ayyagari A, Sharma AK, Prasad KN, et al. Spectrum of opportunistic infections in HIV infected cases in a tertiary care hospital. Indian J Med Microbiol 1999;17:78-80.

[9] Mishra S, Rukadikar A. Prevalence of pulmonary TB in HIV positive individuals, its sensitivity and association with CD4 count. International Journal of Current Microbiology and Applied Science 2015;4(6):292-304. 